\title{
Serum Procalcitonin: as a Triage Tool for Severe Plasmodium falciparum Malaria
}

Manoj Kumar Mohapatra*, Ancil George Thomas, Prafulla Kumar Bariha and Dilip Kumar Patel

Department of Medicine, V.S.S Medical College, Burla, Odisha, India

\begin{abstract}
Objective: Patients of severe falciparum malaria may present with multi organ failure requiring critical care management. Procalcitonin (PCT) can be used as a triage tool to discriminate such patients.

Methods: We determined serum PCT semi-quantitatively by immunochromatographic test in 41 patients of severe and in 19 cases of uncomplicated falciparum malaria. The diagnosis of malaria was made with detection of the parasite from peripheral blood smear. All patients were subjected to detail clinical, biochemical, and haematological work up. The diagnosis of severe malaria was done according to WHO criteria and the severity of organ dysfunction was assessed with Malaria Severity Score (MSS) in all patients by taking different physiological parameters into consideration. The risk stratification of severe malaria was determined with MSS and it is compared with PCT level.
\end{abstract}

Results: Out of 41 patients of severe falciparum malaria $39(95.1 \%)$ patients had multiple complications and 2 $(4.9 \%)$ had single complication. The mean MSS was $8.39 \pm 4.35$. According to MSS, patients were categorized in to low, intermediate, and high risk group in $4(9.7 \%), 9(21.9 \%)$, and $28(68.3 \%)$ patients respectively. Estimation of PCT showed that $13(31.7 \%)$ patients of severe malaria had PCT value within $2-10 \mathrm{ng} / \mathrm{ml}$ (moderately raised) and $28(68.3 \%)$ patients had $\geq 10.0 \mathrm{ng} / \mathrm{ml}$ (highly raised). High risk patients according to MSS were categorized as critical malaria. PCT could able to diagnose such cases with excellent sensitivity and specificity.

Conclusion: S. PCT $\geq 10.0$ could able to define critical malaria and can be conveniently used as a triage tool for management of severe falciparum malaria. Instead of MSS, PCT enhanced triage will save time and decrease the overall costs while achieving similar result.

Keywords: Biomarker; Critical malaria; Complicated malaria; Malaria severity score; Multi organ dysfunction

\section{Introduction}

Still in the second decade of $21^{\text {st }}$ century, malaria remains as a common parasitic disease of the globe with high mortality and morbidity affecting about 216 million and causing death in 655 thousand people [1]. Out of 4 species of Plasmodia that cause human malaria, $P$. falciparum is notorious for its high case-fatality rate and almost all deaths are attributed to this species [2].

In non-immune individuals, early diagnosis and treatment with appropriate antimalarials lead to recovery within few days. On the contrary, a late diagnosis and/or delayed therapy may lead to the development of various complications causing death. At present, complicated malaria is no more limited to anaemia, cerebral malaria or renal failure. Though it is conventional to describe various complications of falciparum malaria in isolation, clinical reality, however, are that majority of patients present with combined complications with different grades of severity leading to multiple organ failure [3]. We observed that the mortality due to severe malaria is directly related to number of organs involved and the severity of organ dysfunction [3]. Once multi organ dysfunction develops antimalarials along with organ support is mandatory for treatment of such patients in intensive care setting $[3,4]$. Therefore there is a necessity to identify such patients who are at high risk of mortality for intensified care and treatment. As there is no tool to assess the severity objectively, we developed Malaria Severity Score (MSS), an objective model to define, assess the severity of organ dysfunction, and to estimate the probability of mortality risk in severe falciparum malaria [5]. Accordingly, for the management we triaged the patients into low (Score $\leq 5$ ), intermediate (Score 6-11), and high risk (Score $\geq 12$ ) [5]. Patients with high risk require intensive treatment; hence we coined "critical" malaria for such patients and other two groups as "non-critical" malaria. But for assessment of organ dysfunction and to calculate the MSS, one needs various investigations and determination of different physiological parameters at the time of admission which is time taking and may not be feasible in low resource settings or even in tertiary care hospital near the bed side at the time of admission. Therefore there is a need to find out a biomarker that can be detected easily and can be used as a tool to distinguish "critical" malaria from "non-critical" severe malaria at the entry for prompt management.

Procalcitonin (PCT) is a prohormone of calcitonin that is found elevated in bacterial infection. In sepsis, serum PCT levels correlate well with severity of sepsis and outcome. Increased levels of serum PCT have also been described in P. falciparum malaria [6,7]. It has been demonstrated that PCT level in P. falciparum malaria correlate with parasitic count and disease severity $[8,9]$. Therefore, in this study we investigate the use of PCT as a biomarker to triage the patients of severe falciparum malaria to provide prompt intensive care management.

\section{Materials and Methods}

The study was undertaken in the Department of General Medicine, Veer Surendra Sai Medical College, Burla in Sambalpur District of Odisha, India from October 2011 to September 2012. After taking

*Corresponding author: Manoj Kumar Mohapatra, Department of Medicine V.S.S. Medical College, Burla, Sambalpur, Odisha, India, Tel: 9437058991 Fax: 0663 2430768; E-mail: mohapatra.manoj@rediffmail.com

Received October 16, 2013; Accepted November 08, 2013; Published November 11,2013

Citation: Mohapatra MK, Thomas AG, Bariha PK, Patel DK (2013) Serum Procalcitonin: as a Triage Tool for Severe Plasmodium falciparum Malaria. Trop Dis 1: 123. doi: 10.4172/2329-891X.1000123

Copyright: () 2013 Mohapatra MK, et al. This is an open-access article distributed under the terms of the Creative Commons Attribution License, which permits unrestricted use, distribution, and reproduction in any medium, provided the original author and source are credited. 
clearance from the Institutional Ethical Committee, 60 patients of $P$. falciparum malaria were enrolled in this study. The diagnosis of falciparum malaria was made with detection of asexual form of the parasite in the Giemsa stained Peripheral Blood Smears (PBS). Parasite counts were expressed as numbers of asexual parasites per micro liter of blood and were calculated from the numbers of parasitized cells per 200 leukocytes in a thick film stained with Giemsa stain i.e. No. of parasites X total leukocyte count / 200.

At the time of hospitalization, patients were evaluated through a detailed clinical history, physical examination and investigations according to the proforma of the study. The Glasgow Coma Scale score was calculated.The systolic blood pressure ( $\mathrm{mm}$ of $\mathrm{Hg}$ ), heart rate/ $\mathrm{min}$, respiration rate/min \& urine output (1/day) was recorded. Blood was collected for estimation of complete blood count, blood (b) urea, serum (s.) creatinine, b. glucose, s. bilirubin, SGOT, SGPT, Alkaline Phosphatase (ALP), s. sodium and potassium. Severe falciparum malaria was defined according to the criteria of WHO [2]. We calculated Malaria Severity Score (MSS) for each patient in 3 stages. First, organ dysfunction was defined according to the criteria. Accordingly, we defined central nervous system, renal, hepatic, respiratory, cardio vascular, haematological, and metabolic dysfunction. Secondly, from different values severity score for each organ dysfunction was calculated, and lastly the score of individual organ dysfunction was added to find out the total MSS from which the probability of mortality was calculated [5]. From the score we triaged the patients into low risk $($ Score $\leq 5)$, intermediate risk (Score 6-11), and high risk (Score $\geq 12$ ) [5]. Patients of low and intermediate risk were treated in general ward and in High Dependency Unit (HDU) according to availability of beds. Patients of high risk were treated in Intensive Care Unit (ICU). All the patients were treated with injection Artesunate as per WHO guideline [10]. Additional organ supportive treatments were given. Dialysis, electrolytes and fluid management was done as per requirement. Blood transfusion is given to patients of severe anaemia. Convulsion was managed by Inj. Phenytoin sodium and or Inj. Lorazepam [4]. Patients with ARDS were kept on ventilator when required. All patients were followed up weekly for 8 weeks to assess the renal function.

Blood was collected for estimation of serum PCT, Erythrocyte Sedimentation Rate (ESR), and C-reactive protein (CRP). S. PCT was estimated semi quantitatively by using B.R.A.H.M.S PCT-Q (B.R.A.H.M.S, Aktiengesellschaft Neuendorfstrasse 25 D-16761 Hennigsdorf, Germany). Depending on the level of PCT, results were classified as "normal" (negative result or a PCT $<0.5 \mathrm{ng} / \mathrm{ml}$ ), "low" (PCT between 0.5-2.0 ng/ml), "moderate" (PCT between 2.0-10.0), and "high" (PCT of $10.0 \mathrm{ng} / \mathrm{ml}$ and above) [11].

All cases who presented with features suggestive of sepsis, malaria infected by species other than P. falciparum or cases of mixed malaria species, non-infectious diseases like diabetes mellitus, chronic renal failure, chronic liver disease, rheumatic heart disease, coronary artery disease, and pregnancy were excluded as it significantly alters the S. PCT levels.

The statistical analysis was performed using IBM SPSS Statistics Version 20. For comparison between groups, the Mann-Whitney $U$ test or Chi square test was used as appropriate. P-value of $<0.05$ was considered to be statistically significant. The sensitivity, specificity, positive and negative predictive value of S. PCT was calculated taking MSS as the standard in this study. The performance of the various variables like ESR, CRP, and S. PCT were quantified by calculating the area under the Receiver Operating Characteristic (ROC) curve.

\section{Results}

The study included 60 patients of $P$. falciparum malaria of which $41(67.2 \%)$ patients suffered from Severe Malaria (SM) and the remaining 19 (31.8\%) patients had Uncomplicated Malaria (UM). Of the 41 patients with SM, 23(56.1\%) patients were male and 18 (43.9\%) were female. Patients of SM presented either with single or multiple complications. The complications according to WHO criteria were: cerebral malaria $(n=2,4.9 \%)$, cerebral malaria+Jaundice $(n=8,19.5 \%)$, cerebral+anaemia $(n=4,9.7 \%)$, cerebral malaria+Jaundice+renal failure $(\mathrm{n}=10,24.4 \%)$, cerebral malaria+Jaundice+renal failure+anaemia $(\mathrm{n}=7, \quad 17.1 \%)$, cerebral malaria+Jaundice+renal failure+Acute Respiratory Distress Syndrome (ARDS) ( $\mathrm{n}=5,12.2 \%)$, cerebral malaria+Jaundice+ARDS+shock $(n=5,12.2 \%)$. Out of 41 patients of SM, single organ involvement was found in only 2 (4.9\%) patients and multi-organ involvement was found in rest 39 (95.1\%) patients. Further, we determined the organ dysfunction and calculated the MSS for each patient. The mean MSS was $8.39 \pm 4.35$. Nine (21.9\%) patients had MSS within 6 to 11 and grouped in intermediate risk where as 28 (68.3\%) patients had the score $\geq 12$ and grouped as high risk. Four (9.7\%) patients of severe malaria had MSS $\leq 5$ (low risk).

The base line investigations and other parameters were mentioned in Table 1. It is evident that patients with SM had higher ESR, CRP, S. creatinine, S. lactate dehydrogenase and S. bilirubin concentration and the lower haemoglobin concentration and platelet count on admission

\begin{tabular}{|c|c|c|c|}
\hline Characteristics & $\begin{array}{l}\text { Uncomplicated } \\
\text { P.falciparum } \\
\text { Malaria }\left(n^{*}=19\right)\end{array}$ & $\begin{array}{c}\text { tSevere } \\
\text { P.falciparum Malaria } \\
\qquad(n=41)\end{array}$ & P Value \\
\hline Age & $37.84 \pm 15.5 \#$ & $37.10 \pm 13.238$ & $N S^{* *}$ \\
\hline $\operatorname{Sex}(M / F)$ & $12 / 7$ & $23 / 18$ & NS \\
\hline WBC $\left(\times 10^{3}\right) \quad\left(/ \mathrm{mm}^{3}\right)$ & $7.89 \pm 3.22$ & $8.01 \pm 3.47$ & 0.009 \\
\hline $\operatorname{RBC}\left(\times 10^{6}\right)\left(/ \mathrm{mm}^{3}\right)$ & $4.44 \pm 0.75$ & $4.24 \pm 1.01$ & NS \\
\hline Hemoglobin (gm/dl) & $11.31 \pm 0.93$ & $9.61 \pm 2.44$ & 0.008 \\
\hline Hematocrit (\%) & $36.26 \pm 3.31$ & $35.91 \pm 4.06$ & NS \\
\hline Platelet $\left(\times 10^{3}\right)\left(/ \mathrm{mm}^{3}\right)$ & $160.32 \pm 54.35$ & $141.59 \pm 65.02$ & NS \\
\hline Parasitic count $\left(\mathrm{Nu} . / \mathrm{mm}^{3}\right)$ & $4569.58 \pm 178.9$ & $8578.82 \pm 214.56$ & 0.001 \\
\hline B.Urea (mg/dl) & $22.21 \pm 6.77$ & $89.34 \pm 49.52$ & 0.0001 \\
\hline S.Creatinine (mg/dl) & $0.86 \pm .23$ & $3.62 \pm 2.04$ & 0.0001 \\
\hline FBS (mg/dl) & $135.42 \pm 37.92$ & $125.02 \pm 35.75$ & NS \\
\hline S.Bilirubin (mg/dl) & $1.06 \pm 0.32$ & $2.25 \pm 1.70$ & 0.02 \\
\hline SGOT (U/L) & $87.58 \pm 37.96$ & $91.27 \pm 39.47$ & NS \\
\hline SGPT (U/L) & $71.52 \pm 37.17$ & $75.97 \pm 36.39$ & NS \\
\hline S.ALP (U/L) & $71.94 \pm 43.99$ & $89.48 \pm 28.31$ & NS \\
\hline GCS & 15 & $8.95 \pm 3.83$ & 0.0001 \\
\hline Urine Output (ml/24 hrs) & $1881.58 \pm 404.218$ & $1020.73 \pm 616.24$ & 0.0001 \\
\hline Heart Rate (nu./min) & $80.63 \pm 7.94$ & $95.27 \pm 20.02$ & 0.002 \\
\hline Systolic BP (mm of Hg) & $116 \pm 12.20$ & $97.32 \pm 21.22$ & 0.010 \\
\hline Respiratory Rate (nu./min) & $21.47 \pm 8.61$ & $22.68 \pm 8.08$ & NS \\
\hline ESR (mm 1st hour) & $18.21 \pm 7.53$ & $36.29 \pm 17.57$ & 0.0001 \\
\hline $\mathrm{LDH}(\mathrm{U} / \mathrm{L})$ & $440.74 \pm 106.53$ & $736.34 \pm 176.120$ & 0.0001 \\
\hline CRP (mg/L) & $33.05 \pm 8.605$ & $51.61 \pm 14.38$ & 0.0001 \\
\hline Malaria Score & 0.0 & $8.39 \pm 4.35$ & 0.0001 \\
\hline
\end{tabular}

${ }^{*}$ n-number, **NS-not significant

\# - Values are expressed as mean \pm standard deviation (SD)

Table 1: General characteristics and laboratory findings of Severe falciparum malaria. 
than UM. Serum PCT concentration was higher among the patients of SM than UM (Table 2). Other acute phase reactants like ESR, CRP, and $\mathrm{LDH}$ were also raised among patients of SM.

Compared to MSS, the sensitivity, specificity, positive and negative predictive value of CRP at the cut-off value of $30 \mathrm{mg} / \mathrm{l}$ was $90.2 \%(95 \%$ CI, $76.85 \%$ to $97.22 \%$ ), $47.37 \%$ (CI, $24.49 \%$ to $71.10 \%$ ), $78.72 \%$ (CI, $64.33 \%$ to $89.28 \%$ ), and $69.23 \%$ (CI, $38.61 \%$ to $90.72 \%$ ) respectively. The sensitivity, specificity, positive and negative predictive value of ESR at the cut-off value of $15 \mathrm{~mm} \mathrm{1st}$ hour was $68.85 \%$ ( $95 \%$ CI, $49.41 \%$ to $79.90 \%$ ), $68.42 \%$ (CI, $43.46 \%$ to $87.35 \%$ ), $81.82 \%$ (C, $64.53 \%$ to $92.98 \%$ ), $48.15 \%$ (CI, $28.68 \%$ to $68.04 \%$ ) respectively. For S. PCT the above parameters at different cut-off values were mentioned in Table 3. When PCT of $2.0 \mathrm{ng} / \mathrm{ml}$ was taken as cut-off value it had excellent sensitivity for severe malaria, where as specificity was poor. At a cut-off value of $>10.0 \mathrm{ng} / \mathrm{ml}$, the sensitivity was 0.67 and specificity was 0.94 . ROC was drawn for the performance of three variables to discriminate the patients of severe malaria requiring critical care (Figure 1). It was quantified by calculating area under ROC. It was 0.915 (95\% CI, 0.687 to 0.908$)$ for PCT compared to $\operatorname{ESR}(0.797,95 \%$ CI 0.548 to 0.876$)$ and CRP $(0.855,95 \%$ CI 0.675 to 0.904$)$ suggesting that PCT provides the most accurate diagnostic performance among the three. Scatter diagram showed a direct correlation between MSS and PCT (Figure 2). Out of 28 patients of SM with high risk, $12(42.8 \%)$ patients died with an overall mortality of $20.0 \%$ ( 12 of 60 ). All the patients who died had multiple complications. There was no death among the patients of UM and of SM with low and intermediate risk.

\section{Discussion}

Earlier we found that multi organ dysfunction is the leading cause of death in SM [3-5]. Therefore, we categorized the patients of severe falciparum malaria who were seriously ill mostly due to multiorgan involvement requiring treatment in Intensive Care Unit (ICU) as "critical" malaria. The diagnosis of "critical" malaria was done objectively with MSS. The present study showed that serum PCT is a

\begin{tabular}{|l|c|c|c|}
\hline $\begin{array}{l}\text { S.Procalcitonin } \\
\text { (in ng/ml) }\end{array}$ & $\begin{array}{c}\text { Uncomplicated } \\
\text { P.falciparum } \\
\text { Malaria }\end{array}$ & $\begin{array}{c}\text { Severe } \\
\text { P.falciparum } \\
\text { Malaria }\end{array}$ & P value \\
\hline Normal(<0.5) & 7 & 0 & 0.001 \\
\hline Low (0.5-2) & 7 & 0 & 0.001 \\
\hline Moderate (>2-10) & 4 & 13 & 0.001 \\
\hline High ( $\geq 10)$ & 1 & 28 & 0.001 \\
\hline Total & 19 & 41 & \\
\hline
\end{tabular}

Table 2: Comparison of S.PCT in uncomplicated and severe falciparum malaria.

\begin{tabular}{|l|l|l|l|}
\hline & \multicolumn{3}{|c|}{$\begin{array}{c}\text { Procalcitonin Cut-off Points } \\
2.0 \\
\text { ng/ml }\end{array}$} \\
\hline Sensitivity & $\begin{array}{l}100.00 \% \\
(91.31 \% \text { to } 100.00 \%)^{*}\end{array}$ & $\begin{array}{l}100.00 \% \\
(91.31 \% \text { to } 100.00 \%)^{*}\end{array}$ & $\begin{array}{l}68.29 \% \\
(51.91 \% \text { to } 81.90 \%)^{*}\end{array}$ \\
\hline Specificity & $\begin{array}{l}36.84 \% \\
(16.35 \% \text { to } 61.62 \%)^{*}\end{array}$ & $\begin{array}{l}63.16 \% \\
(38.38 \% \text { to } 83.65 \%)^{*}\end{array}$ & $\begin{array}{l}94.74 \% \\
(73.90 \% \text { to } 99.12 \%)^{*}\end{array}$ \\
\hline $\begin{array}{l}\text { Positive } \\
\text { predictive } \\
\text { value }\end{array}$ & $\begin{array}{l}77.36 \% \\
(63.79 \% \text { to } 87.70 \%)^{*}\end{array}$ & $\begin{array}{l}85.42 \% \\
(72.23 \% \text { to } 93.90 \%)^{*}\end{array}$ & $\begin{array}{l}96.55 \% \\
(82.17 \% \text { to } 99.42 \%)^{*}\end{array}$ \\
\hline $\begin{array}{l}\text { Negative } \\
\text { predictive } \\
\text { value }\end{array}$ & $\begin{array}{l}100.00 \% \\
(58.93 \% \text { to } 100.00 \%)^{*}\end{array}$ & $\begin{array}{l}100.00 \% \\
(73.35 \% \text { to } 100.00 \%)^{*}\end{array}$ & $\begin{array}{l}58.06 \% \\
(39.08 \% \text { to } 75.44 \%)^{*}\end{array}$ \\
\hline
\end{tabular}

* WITH 95\% CONFIDENCE INTERVAL

Table 3: Descriptive statistics of the accuracy of S. PCT using various cut-off points. useful biomarker of falciparum malaria to distinguish critical malaria among patients of SM. S. PCT $\geq 10.0 \mathrm{ng} / \mathrm{ml}$ can diagnose patients of $\mathrm{SM}$ as critical malaria at the time of admission which is comparable to MSS. However, if the cut-off value was kept at $2.0 \mathrm{ng} / \mathrm{ml}$, no case will be denied rigorous monitoring and intensive treatment but it may not be cost effective as they can be safely managed in non-ICU setting. If we apply a cut-off value of $10 \mathrm{ng} / \mathrm{ml}$ we may be able to correctly classify the patients into having SM requiring critical care.

PCT is a pro-hormone of calcitonin containing 116 amino acids with a molecular weight of $13 \mathrm{kDA}$. Under physiological conditions, calcitonin is produced and secreted from C-cells of thyroid gland after intracellular proteolysis to circulation with plasma half life of a few minutes. Therefore, under normal condition PCT level is low $(<0.5 \mathrm{ng} / \mathrm{ml})$ [12]. However, to define sepsis serum PCT level $<0.2$ $\mathrm{ng} / \mathrm{ml}$ is found more sensitive. Therefore, PCT level is $<0.2 \mathrm{ng} / \mathrm{ml}$ is recommended to consider as normal [13]. But for the present study as per the recommendation of the manufacturer's guideline we accepted PCT level $<0.5 \mathrm{ng} / \mathrm{ml}$ as normal [11]. PCT is found elevated in bacterial infection in response to inflammation and in addition to PCT, other

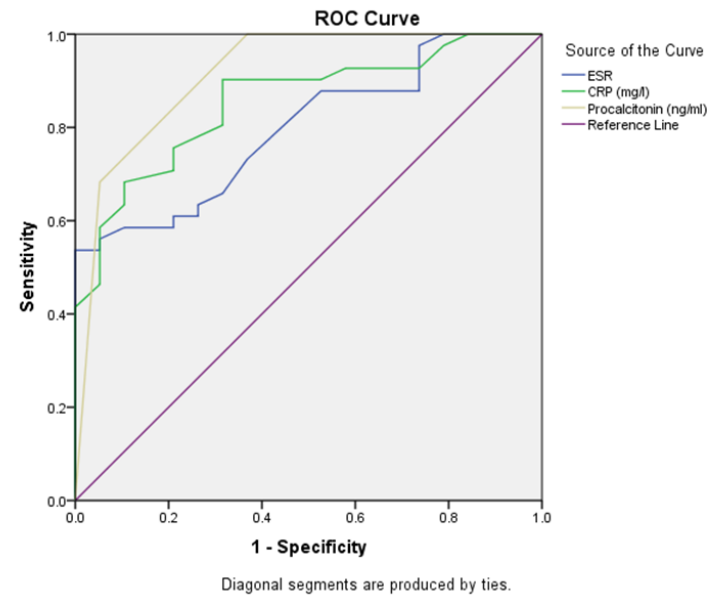

Figure 1: Roc Curve.

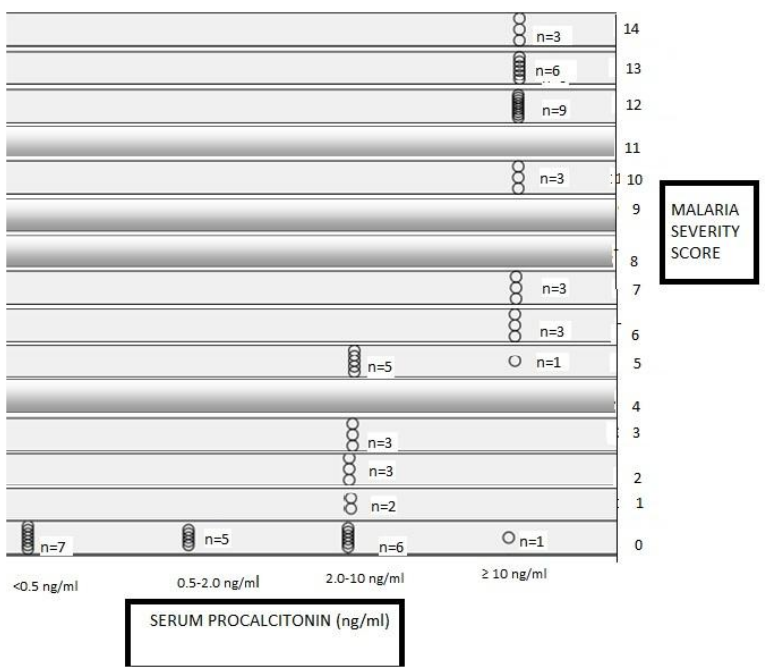

$X$ axis: Procalcitonin, $Y$ axis- Malaria Severity Score. $n=$ number

Figure 2: Scatter diagram showing the relation between MSS and S.PCT. 
inflammatory mediators like IL-6, TNF, and acute phase reactants like ESR, CRP are also raised. Out of all, PCT is found to be elevated in bacterial infection and correlate well with severe sepsis and septic shock i.e. when organ dysfunction is present [14]. The origin of PCT in infection is thought to be extrathyroidal and the predominance of PCT without increase in calcitonin indicates the presence of a constitutive pathway within the cell that bypasses the enzymatic conversion of PCT to calcitonin [12]. Bacterial infection induces a ubiquitous increase of CALC-1 gene expression and release of PCT from all parenchymal cells and differentiated cell types throughout the body [12]. The release of PCT can be induced either directly by microbial toxins (endotoxin) or indirectly by a humoral or cell-mediated host response (e.g. IL-1 $\beta$, TNF, IL-6) $[12,14]$. It is notable that PCT level did not increase in viral infection and auto immune disorders. However, significantly higher concentration of serum PCT was found in SM than UM [8,9]. Its level also correlated with parasite density and can be used as marker of severity. In all the studies associated infection was excluded, suggesting the role of malaria parasite for the rise of PCT $[15,16]$. PCT is also induced by pro-inflammatory cytokines, tissue trauma, and poor microcirculatory blood flow [12]. In falciparum malaria IL-6, TNF were found to increase and impairment of microcirculatory blood flow due to blockade by the parasitized RBC has a pathogenetic role in SM [2]. All these factors may induce production of PCT in falciparum malaria.

The present study showed that PCT is raised in SM and its level directly correlated objectively with the severity as assessed by MSS. PCT determination was also found useful among patients of SM as a point of care test among the travelers with malaria [15]. But no other study correlates the rise of PCT with severity objectively. Once a patient diagnosed as falciparum malaria then PCT estimation will further help to categorize the patients of severe malaria as critical malaria. Serum PCT along with other acute phase reactants like ESR and CRP were also found raised in SM but S. PCT was found to provide the most accurate diagnostic performance among the three. High negative predictive value of S. PCT may be helpful for a rapid exclusion of critical malaria on admission. When S. PCT was $\leq 2 \mathrm{ng} / \mathrm{ml}$ the patients can be managed in the general ward or domiciliary treatment may be given; with 2-10 $\mathrm{ng} / \mathrm{ml}$ the patients can be managed in the general ward with special attention or in High Dependency Unit (HDU) and can be shifted to ICU when necessary; and if more than $10 \mathrm{ng} / \mathrm{ml}$ the patients should be shifted to ICU for management. Hence, PCT is an additional investigation tool to triage the patients of SM. There are some limitations of this study. We collected data from only one tertiary hospital and, so the external validity of the results may have to be evaluated further. A quantitative assay of serum PCT could not be done which may have improved the prediction of our diagnostic accuracies. So we failed to derive the predictive value of S. PCT as a marker of mortality.
In developing countries intensive care facilities are limited and failure to identify critically ill patients of severe malaria will increase the mortality. So we conclude that semi-quantitative assay of S. PCT can be conveniently used at the bed side to triage the patients of SM rapidly to institute intensive care management without reference to a laboratory.

\section{References}

1. World malaria report: 2011

2. (2000) Severe falciparum malaria. World Health Organization, Communicable Diseases Cluster. Trans R Soc Trop Med Hyg 94: S1-S90.

3. Mohapatra MK (2006) The natural history of complicated falciparum malaria--a prospective study. J Assoc Physicians India 54: 848-853.

4. Mohapatra MK, Dash LK, Mishra NR, Agrawala RK (2012) Profile of seizures in adult falciparum malaria and the clinical efficacy of phenytoin sodium for contro of seizures. Asian Pacific J Trop Dis s558-s562.

5. Mohapatra MK, Das SP (2009) The malaria severity score: a method for severity assessment and risk prediction of hospital mortality for falciparum malaria in adults. J Assoc Physicians India 57: 119-126.

6. Muñoz P, Simarro N, Rivera M, Alonso R, Alcalá L, et al. (2004) Evaluation of procalcitonin as a marker of infection in a nonselected sample of febrile hospitalized patients. Diagn Microbiol Infect Dis 49: 237-241.

7. Jones AE, Fiechtl JF, Brown MD, Ballew JJ, Kline JA (2007) Procalcitonin tes in the diagnosis of bacteremia: a meta-analysis. Ann Emerg Med 50: 34-41.

8. Al-Nawas B, Shah P (1997) Procalcitonin in acute malaria. Eur J Med Res 2: 206-208.

9. Chiwakata CB, Manegold C, Bönicke L, Waase I, Jülch C, et al. (2001) Procalcitonin as a parameter of disease severity and risk of mortality in patients with Plasmodium falciparum malaria. J Infect Dis 183: 1161-1164.

10. World Health Organization (2010) Guidelines for the treatment of malaria. 2nd ed: $35-47$.

11. Instruction manual BRAHMS PCT-Q (2011) Thermo Scientific, Version R14en: 1-4.

12. Müller B, White JC, Nylén ES, Snider RH, Becker KL, et al. (2001) Ubiquitous expression of the calcitonin-i gene in multiple tissues in response to sepsis. J Clin Endocrinol Metab 86: 396-404.

13. Wacker C, Prkno A, Brunkhorst FM, Schlattmann P (2013) Procalcitonin as a diagnostic marker for sepsis: a systematic review and meta-analysis. Lancet Infect Dis 13: 426-435.

14. Aikawa N, Fujishima S, Endo S, Sekine I, Kogawa K, Yamamoto Y, et al. (2005) Multicenter prospective study of procalcitonin as an indicator of sepsis. J Infect Chemother 11:152-59.

15. Hesselink DA, Burgerhart JS, Bosmans-Timmerarends $H$, Petit $P$, van Genderen PJJ (2009) Procalcitonin as a biomarker for severe Plasmodium falciparum disease: a critical appraisal of a semi-quantitative point-of-care test in a cohort of travellers with imported malaria. Malaria J 8: 206.

16. Manegold C, Schmiedel S, Chiwakata CB, Dietrich M (2003) Procalcitonin serum levels in tertian malaria. Malar J 2: 34. 